\title{
PENATAAN ELEMEN SIRKULASI VERTIKAL PADA GEDUNG UNPAR JL.MERDEKA NO.30 BANDUNG MELALUI PENDEKATAN SPACE SYNTAX DAN KRITERIA HERITAGE
}

\author{
Rachadian. $\mathrm{H}^{1}$, Yohanes K Kusliansjah \\ Universitas Katolik Parahyangan \\ 1rachadian.h@gmail.com
}

\begin{abstract}
Abstrak: Terdapat kebutuhan akan sarana sirkulasi vertikal yang lebih mudah, terutama mengingat kebutuhan bagi difabe dan orang tua pada bangunan-bangunan bersejarah, terutama pada bangunan yang masih difungsikan sebagai bangunan publik hingga saat ini. Hal ini karena pada umumnya bangunan-bangunan tersebut menggunakan tangga sebagai sarana sirkulasi vertikal sedangkan aktivitas yang ada didalamnya telah meningkat sehingga diperlukan sirkulasi vertikal yang lebih efisien seperti lift. Permasalahannya adalah menentukan perletakan sarana sirkulasi vertikal pada bangunan bersejarah, yang kadang tidak mengakomodasi perletakan sarana sirkulasi vertikal baru dan perletakan tersebut haruslah pada lokasi yang mudah dicapai dan dilihat pengguna namun disaat yang sama juga tetap memperhatikan kiadah-kaidah aturan konservasi bangunan. Penelitian ini bertujuan untuk memperlihatkan penggunaan metode Space Syntax dapat digunakan bersamaan dengan kajian konservasi bangunan bersejarah untuk menentukan perletakan sarana sirkulasi vertikal pada bangunan sebagai alat kajian ruang yang akan menentukan lokasi perletakan dari segi pencapaian dan keterhubungan ruang yang kemudian hasil penilaian tersebut akan digunakan untuk menentukan perletakan elemen baru pada bangunan dengan tetap memperhatikan kaidah-kaidah konservasi cagar budaya. Penelitian menggunakan metode kuantitatif simulasi ekseprimental dengan penggunaan program komputer Depthmap sebagai alat untuk analisa simulasi metode Space Syntax, didukung oleh ketentuan-ketentuan heritage sebagai panduan batasan perubahan yang diizinkan pada bangunan cagar budaya. Hasil Penelitian menunjukan penggunaan Space Syntax dapat digunakan bersamaan dengan analisis kajian konservasi bangunan untuk menentukan perletakan lift pada lokasi yang memperhatikan kajian kemudahan pencapaian dan observasi dari pengguna namun tetap memperhatikan pengaruh perletakan tersebut pada elemen-elemen sejarah dan arsitektural bangunan yang ditunjukan pada studi kasus gedung UNPAR Jl.merdeka no.30 Bandung
\end{abstract}

Kata Kunci: Sirkulasi Vertikal, Lift, Space Syntax, Heritage

\begin{abstract}
There is a need for easier vertical circulation facilities, especially given the need for people with disabilities and parents in historic buildings, especially in buildings that still function as public buildings to date. This is because in general these buildings use stairs as a means of vertical circulation while the activities inside have increased so that more efficient vertical circulation is needed such as elevators. The problem is how to determine the placement of vertical circulation facilities in historical buildings, which sometimes do not accommodate the placement of new vertical circulation facilities and placement should be in locations that are easily accessible and seen by users but at the same time also pay attention to the rules of building conservation rules. This study aims to show the use of the Space Syntax method can be used in conjunction with the conservation study of historic buildings to determine the placement of vertical circulation facilities in buildings as a space study tool that will determine the location of placement in terms of accesibility and connectedness of space which will then be used to determine placement new elements in the building while paying attention to the principles of cultural heritage conservation. The study used quantitative methods of ekseprimental simulation with the use of Depthmap's computer program as a tool for analysis of simulation of the Space Syntax method, supported by heritage provisions as a guide to limits of changes allowed in cultural heritage buildings. The results showed that the use of Space Syntax can be used in conjunction with the analysis of building conservation to determine elevator placement in locations that pay attention to the study of ease of achievement and observation of users but still pay attention to the influence of the placement on historical and architectural elements of the building shown in the case study of the UNPAR building Jl.merdeka no.30 Bandung.
\end{abstract}

Keywords : Vertical Circulation, Space Syntax, Heritage 


\section{PENDAHULUAN}

Tantangan pada konservasi dan restorasi dari bangunan bersejarah adalah membuat bangunan tersebut berguna, dimana secara umum memerlukan adaptasi terhadap fungsi dan lingkungan sosial baru yang terkadang terdapat ketidaksesuaian dengan konfigurasi ruang aslinya (Amorim, 2007). Bahkan faktanya kebutuhan akan gaya kehidupan modern tidak sejalan atau terinterpretasi dengan baik pada karakteristik bangunan cagar budaya tersebut, sehingga terkadang menuntut intervensi radikal secara arsitektural (Amorim, 2007). Salah satu penyesuaian yang umumnya diperlukan adalah penyesuaian dalam bentuk penataan ruang dan sarana sirkulasi, terutama sarana sirkulasi vertikal. Transportasi vertikal merupakan salah satu elemen penting dalam perencanaan sirkulasi bangunan. Ditinjau dari aturan kelayakan bangunan, kebutuhan akan sirkulasi vertikal yang baik merupakan keharusan, hal tersebut tedapat pada beberapa peraturan seperti Undang-Undang RI nomor 28 tahun 2002 dalam pasal 29 mengenai kemudahan hubungan vertikal, pasal 31 mengenai penyediaan aksesibilitas bagi difable serta Permen PUPR no.14 tahun 2017 tentang persyaratan kemudahan bangunan gedung. Lift adalah salah satu sarana sirkulasi vertikal yang umumnya digunakan sebagai penyesuaian kebutuhan tersebut karena mampu mengakomodasi difabel dan mempermudah sirkulasi pengguna. Permasalahnnya adalah pada umumnya tata ruang bangunan cagar budaya yang cukup tua tidak memiliki dan tidak dipersiapkan untuk mengakomodasi penambahan sirkulasi vertikal ini. Kondisi ini akhirnya akan menciptakan isu perlunya kajian tata ruang untuk menentukan perletakan sirkulasi vertikal baru yang baik dan tetap menjaga nilai-nilai sejarah dan arsitektural bangunan dengan tidak menghilangkan elemen-elemen arsitektural bangunan yang memiliki nilai, fungsi dan makna tertentu bagi bangunan.

Gedung UNPAR J1.Merdeka No.30 Bandung adalah salah satu bangunan yang mengalami permasalahan tersebut. Gedung bersejarah yang dibangun sekitar tahun 1955 dan masih difungsikan sebagai tempat perkuliahan ini memiliki sarana sirkulasi vertikal berupa tangga yang saat ini terasa kurang nyaman dan cukup melelahkan untuk digunakan sehari-hari. Hal ini dikarenakan struktur tangga yang belum memiliki standard untuk orang Indonesia pada saat dibangun sehingga memiliki anak tangga yang tinggi. Selain itu meskipun hanya tiga lantai tapi jarak antar lantai yang memiliki ketinggian 6 meter, hal ini membuat pengguna, terutama difabel kurang terakomodasi. Di sisi lain, bangunan ini merupakan salah satu bangunan bersejarah dimana terdapat elemen-elemen pada bangunan yang memiliki nilai sejarah dan arsitektural. Sehingga selain kajian mengenai nilai sejarah dan arsitektural bangunan, perlu kajian dalam penataan ruang untuk perletakan sarana sirkulasi yang baru.

Space Syntax merupakan metode dan terapan set analisis ruang, alat kuantitatif dan deskriptif untuk menganalisa formasi spasial dalam bentuk-bentuk yang berbeda : bangunan, kota, ruang interior atau lanskap (Hillier dan Hanson, 1984; Hillier, 1996). Penggunaan Space Syntax dalam bidang konservasi dan pelestarian bangunan telah menjadi objek penelitian yang cukup berkembang, eksplorasi kajian sejarah dengan Space Syntax membuka kemungkinan-kemungkinan lain dalam hasil yang diinginkan (Griffiths, 2012) . Beberapa hasil penelitian menunjukan bahwa Space Syntax dalam dalam konservasi dapat digunakan untuk mengkonservasi ruang (Amorim, 2007), menganalisa sejarah morfologi bangunan (Razon, 2017) dan pengaruh kultur sosial lingkungan terhadap perubahan ruang arsitektur (Askarizad, 2017; Adiyanto,2016) atau sebagai kajian untuk perencanaan pengembangan kawasan bersejarah. 
Tujuan penelitian ini adalah memberikan gambaran tahapan serta hasil kajian yang bisa didapat dari penggunaan Space Syntax bersamaan dengan kajian nilai sejarah dan arsitektural bangunan untuk mendapatkan hasil kajian yang bisa digunakan untuk kebutuhan penambahan fasilitas bangunan. Manfaat dari penelitian ini secara khusus adalah sebagai bahan evaluasi pengembangan gedung UNPAR Jl.Merdeka No.30 Bandung berdasarkan kajian ilmiah sebagai pedoman bagi perencanaan, perancangan dan pengambilan keputusan terhadap konservasi, renovasi dan redesain desain tata ruang bangunan. manfaat secara umum adalah memberikan suatu alternative metode kajian bangunan bersejarah yang lebih memperhatikan analisis ruang.

\section{KASUS STUDI DAN METODE PENELITIAN}

\subsection{Kasus Studi}

Penelitian dilakukan pada gedung UNPAR Jl.Merdeka No.30 Bandung. Gedung ini merupakan bangunan perkuliahan pertama yang dibangun sendiri oleh UNPAR. Gedung ini adalah karya dari (Alm) bapak Soesilo, ayahanda dari (Alm) bapak Ir. Suhartono Soesilo, pendiri Fakultas Arsitektur UNPAR. Pembangunan dilakukan sekitar tahun 1950, dimana pada masa itu selain merupakan masa transisi kemerdekaan, juga merupakan masa transisi bagi perkembangan arsitektur Indonesia yang mulai meninggalkan gaya arsitektur kolonial dan beralih ke gaya arsitektur modern dan jengki sebagai salah satu bentuk kebebasan berekspersi. Dengan demikian, bangunan memiliki elemen-elemen arsitektural yang harus dijaga kelestariannya agar nilai sejarah dan keilmuan dari bangunan tetap terjaga. Status sebagai bangunan cagar budaya membuat batasan penambahan dan perubahan pada bangunan terikat dengan aturan-aturan yang berlaku, diantarannya Undang-undang no.11 tahun 2010 tentang cagar budaya pasal 5, PERDA kota Bandung no.10 tahun 2009 BAB VII bagian ke satu pasal 18 tentang kriteria bangunan cagar budaya

Di sisi lain, bangunan termasuk sebagai bangunan publik dengan fungsi pendidikan yang masih aktif digunakan. hal ini membuat bangunan harus mengikuti aturan-aturan kelayakan bangunan yang telah ditetapkan salah satunya adalah aksesibilitas sirkulasi vertikal, seperti yang telah dituliskan pada Undang-Undang RI nomor 28 tahun 2002 dalam pasal 29 mengenai kemudahan hubungan vertikal, pasal 31 mengenai penyediaan aksesibilitas bagi difable serta PermenPUPR no.14 tahun 2017 tentang persyaratan kemudahan bangunan gedung.

Dengan demikian, sebagai bangunan publik maka bangunan perlu melakukan perubahan agar fungsinya sebagai ruang pendidikan dapat diakses oleh berbagai kalangan. Dalam hal ini, Peraturan Menteri no.01/PRT/M 2015 tentang gedung cagar budaya yang dilestarikan, pasal 16 serta Undang-undang no.11 tahun 2010 tentang cagar budaya, pasal 83 memberikan penjelasan mengenai kemungkinan bangunan bersejarah untuk melakukan penyesuaian dengan kebutuhan saat ini serta batasan-batasan yang harus diperhatikan.

Melihat hal-hal diatas, gedung UNPAR Jl.Merdeka No.30 Bandung dipilih menjadi objek penelitian karena memiliki hal-hal yang menjadi tujuan penelitian, yaitu suatu bangunan bersejarah yang memerlukan penyesuaian berupa penambahan fasilitas atau sarana sirkulai vertikal yang lokasi perletakannya didasarkan pada analisis pergerakan manusia dan tata 
ruang agar berfungsi dengan baik namun di sisi lain memerlukan kajian mengenai nilai sejarah dan arsitektural bangunan agar penambahan tersebut tidak merusak nilai-nilai sejarah da arsitektural bangunan.

\subsection{Metode Penelitian}

Metode penelitian yang digunakan adalah pedekatan penelitian kuantitatif simulasi eksperimental, dengan program komputer yang menyajikan data dan pengolahan data atau informasi dalam bentuk tampilan gambar grafis. Instrumen penelitian adalah program Depthmap sebagai alat untuk menganalisa perhitungan sintaks ruang. Peran Sitaksis Ruang dalam konservasi bangunan adalah Menganalisa Sintaks ruang untuk menentukan bentuk dan pola dari konfigurasi ruang objek cagar budaya dengan tujuan mempertahankan "spatial Spirit" (Karimi, Kayvan, London, 2000) Selain itu dilakukan pengumpulan data secara observasi dan kuesioner di lapangan untuk mencari tahu hal-hal yang terjadi secara nyata di kawasan objek studi. Temuan hasil observai ini akan dikomparasi dengan hasil analisis sintaks ruang untuk mendapatkan perbandingan antara desain perencana dengan kondisi sebenarnya.

Tahapan penelitian secara garis besar adalah :

\section{a. Analisis Space Syntax}

Analisis ini akan menghasilkan kajian analisis keterhubungan dan morfologi ruang pada bangunan. Terdapat beberapa metode untuk menggunakan Space Syntax dalam kebutuhan cagar budaya, hal tersebut tergantung dari apa yang ingin dicapai dari analisa sintaks tersebut. Langkah analisa awal, Loureio (Amorim, 2007), Merekomendasikan analisis struktur spasial pada bangunan cagar budaya perlu memperhatikan prosedur sebagai berikut

1) Persiapan data dasar (denah, potongan dan lain-lain)

2) Menganalisa bentuk koneksi, aksial dan properti visibilitas dari bangunan tersebut

3) Mendeskrispikan properti konfigurasi ruang bangunan

4) Mengidetifikasi ketidak sesuaian antara fungsi dan bentuk spasial

5) Mengidentifikasi genotip ruang

6) Mengidentifikasi properti spasial yang relevan untuk dipertahankan (pola aksesibilitas, ruang visual dan lain-lain)

7) Peraturan dan ketentuan pemugaran dan konservasi

8) Memasukan sintesa data spasial sebagai data base bangunan

9) Evaluasi dari proyek pemugaran.

Dalam penelitian ini, hasil analis Space Syntax yang diinginkan adalah penentuan kemungkinan lokasi-lokasi sirkulasi vertikal yang mudah dijangkau dan dapat terlihat dengan mudah dari titik-titik kumpul.

\section{b. Analisis Nilai Sejarah dan Arsitektural Bangunan}

Analisis ini akan menghasilkan kajian berupa elemen-elemen bangunan yang harus dipertahankan sebagai bentuk pelestarian sejarah. Analisa akan menghasilkan elemen-elemen apa saja yang harus dipertahankan dan bisa berubah.

\section{c. Penentuan Lokasi Berdasarkan Kesesuaian Analisis Sejarah Arsitektural Bangunan dan Space Syntax}

Penentuan lokasi akhir lokasi yang paling memungkinkan dari segi pencapaian dan tidak terlalu mengubah atau merusak nilai sejarah arsitektur bangunan. 


\section{HASIL DAN TEMUAN}

\subsection{Kajian Space Syntax}

Analisa Space Syntax betujuan untuk :

$>$ Sebagai bagian dari data bangunan dilihat dari segi analisa teori ruang

$>$ Membaca hubungan satu ruang dengan ruang yang lain serta pengaruh perubahan ruang terhadap hubungan tersebut.

$>$ Hasil dari analisa ini dapat menjadi landasan untuk melakukan perubahan ruang selanjutnya, atau untuk pengembalian fungsi ruang seperti awal desain.

Untuk memprediksi bagaimana pengguna akan bersirkulasi dan menentukan arah pada bangunan, kita dapat menggunakan analisis sintaks dari Isovist dan VGA. Isovist akan memperlihatkan bagaimana jangkauan penglihatan pengguna untuk mensurvei lingkungannya. Dengan demikian kita dapat memprediksi penempatan-penempatan elemen bangunan seperti tangga, penanda arah atau lift agar mudah terlihat dari titik amat yang diinginkan. Sedangkan analisis VGA akan memberikan analisa area-area yang diperkirakan sebagai ruang yang memiliki aktifitas tinggi oleh pengguna.

\section{a. Pertimbangan Analisis VGA}

Meninjau dari sintaks, artinya mencari area yang memiliki nilai integrasi tinggi dan konektivitas yang baik, sehingga penempatan lift didasarkan pada kebutuhan pengamat untuk menemukan jalan termudah. Di dalam graph area tersebut ditandai dengan gradasi dari hijaukuning-merah.

Pada denah lantai dasar, area tersebut paling terlihat pada selasar depan ruang tata usaha, hall dan selasar depan hall ditandai dengan gradasi warna merah hingga hijau. sedangkan pada lantai 2 dan 3 ditunjukan pada area selasar. Hal ini menujukan area tersebut merupakan area dengan aktivitas pergerakan yang cukup tinggi, sehingga bila diletakan lift pada area-aea terebut, orang akan langsung dapat mencapainya
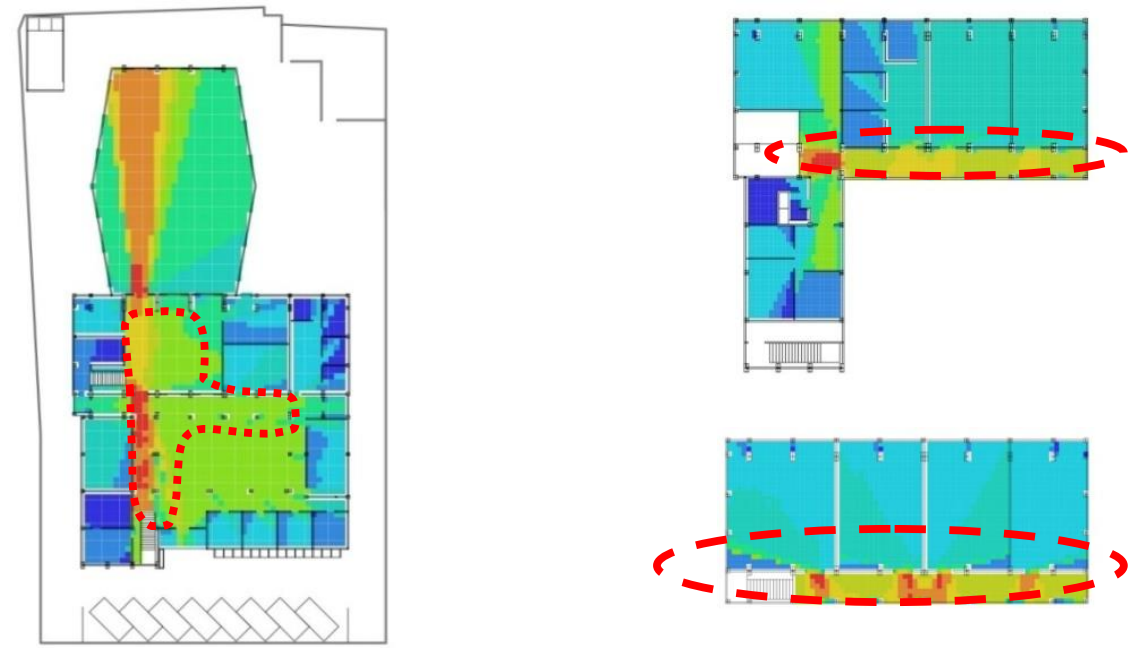

Gambar 1. Perbandingan Graph Sintaks Pada Setiap Lantai 


\section{b. Pertimbangan Analisis Isovists}

Ilustrasi polygon isovist menggambarkan kemampuan pandangan pengamat dari satu titilk ruang konveks terhadap lingkungannya. dengan analisis ini kita bisa memperkirakan kemampuan pandangan pengamat dari titik yang kita inginkan. Pada analisa VGA lantai 1 sebelumnya kita melihat gradasi merah-oranye-kuning hijau dominan pada sisi koridor, artinya disana merupakan area dimana dapat ditentukan sebagai titik-titik pengamatan utama karena menandakan area dengan pergerakan utama. Dari hal tersebut, kita bisa mengambil titik-titik pada area tersebut sebagai analisis Isovist. Dua titik yang diambil adalah pada area di sisi ruang tata usaha dan area di sekitar pintu masuk hall atau setelah pintu masuk samping

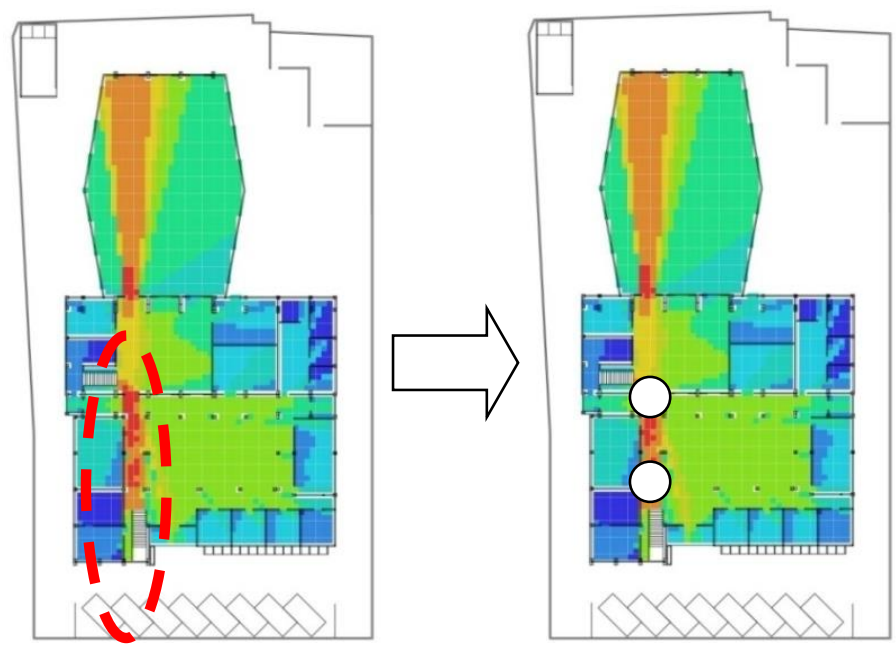

Gambar 2. Penentuan titik pengamatan, ditinjau dari perkiraan area pergerakan utama VGA

Sedangkan pada hasil analisis polygon isovist, pandangan yang didapat adalah sebagai berikut :
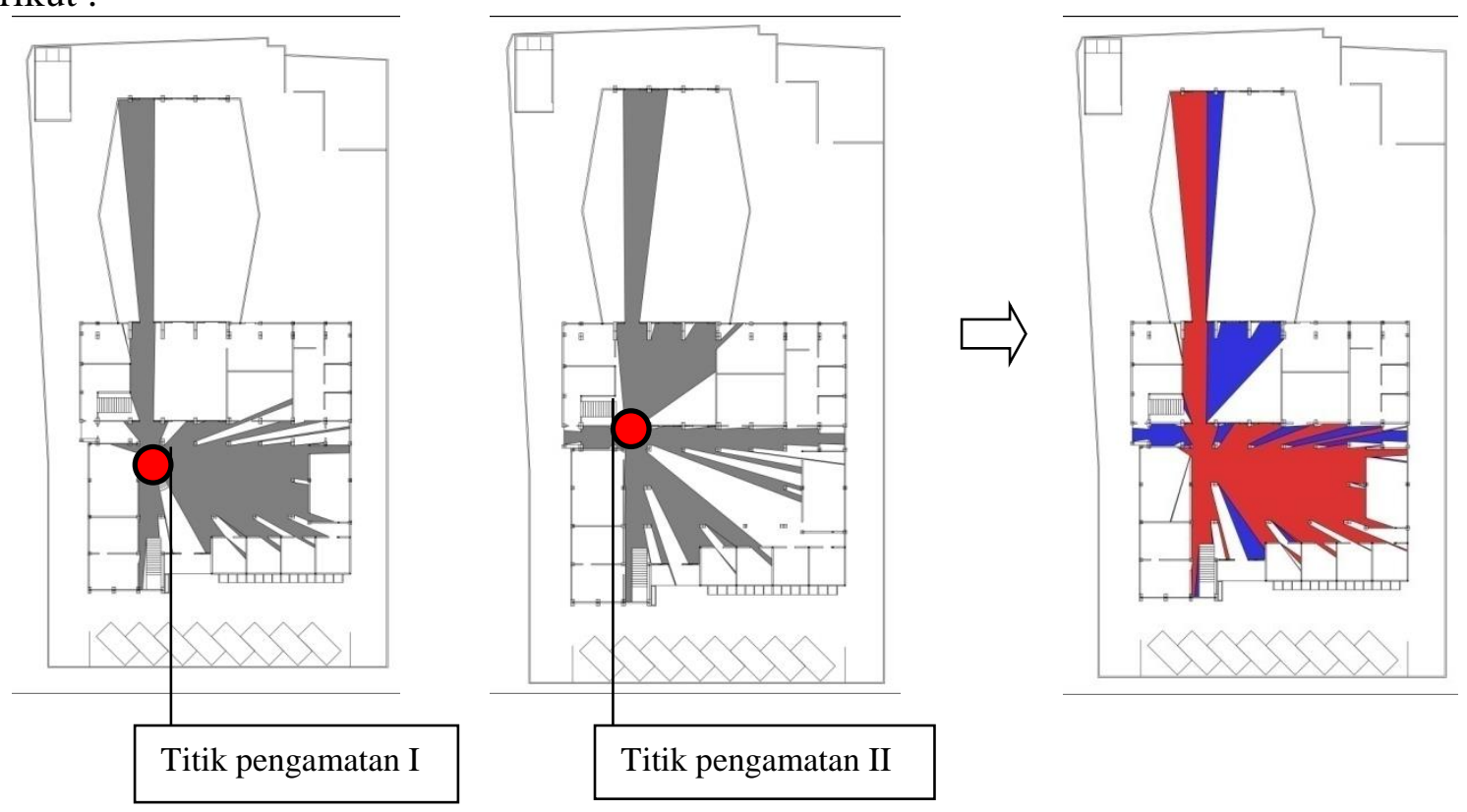

Gambar 3. Pengamatan isovist pada Titik Pengamatan I dan II 
Jika ditinjau dari polygon tersebut, jangkuan area pengamatan dari kedua titik pengamatan tersebut adalah sekitar innercourt, selasar dan hall. kita dapat mengabaikan pandangan ke arah aula karena area tersebut merupakan area tertutup yang bukan termasuk ruang rutinitas umum. Dari analisa awal polygon isovist ini kita bisa menentukan kira-kira perletakan transportasi vertikal yang mudah diamati dan dijangkau dari titik-titik pengamatan.

\section{c. Perkiraan Lokasi - Lokasi Lift Ditinjau Dari Hasil ISovist dan VGA}

Dari hasil Isovist dan VGA, terdapat dua lokasi yang dinilai cukup memadai untuk pemasangan lift, lokasi tersebut adalah pada titik innercourt selasar timur dan ruang yang sebelumya adalah ruang sekretaris.

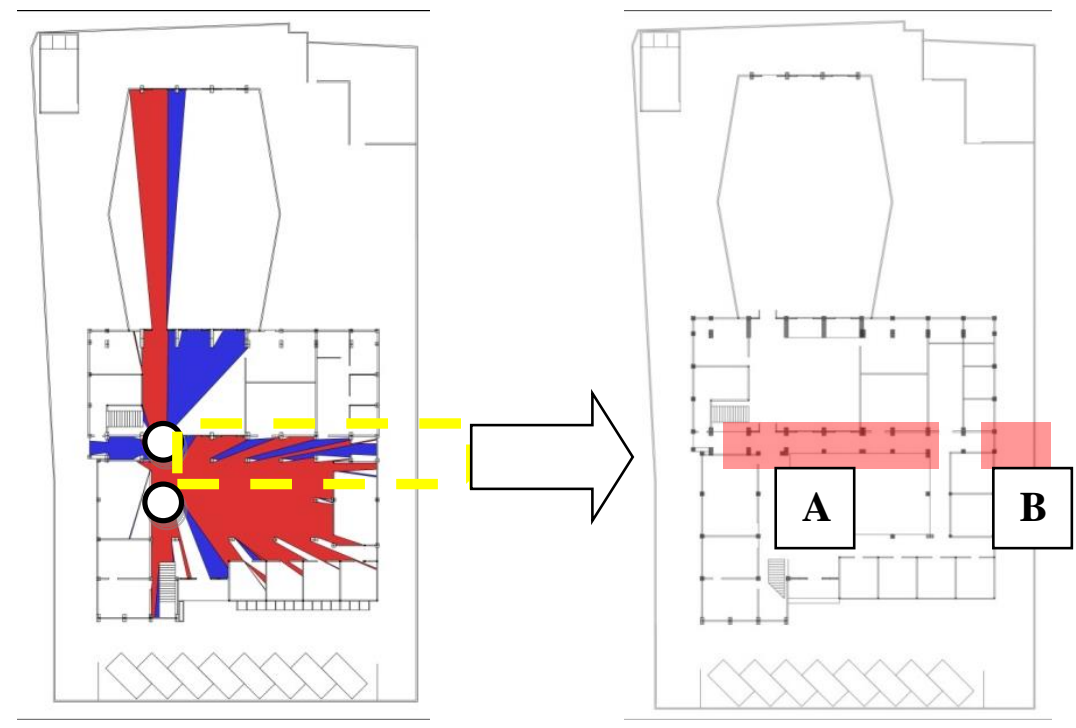

Gambar 4. Lokasi-Lokasi Pilihan pemasangan Lift

Lokasi-lokasi yang didapatkan oleh analisis Space Syntax adalah lokasi yang paling memungkinkan untuk langsung terlihat dan dijangkau dari titik-titik kumpul. Dengan menggabungkan hasil kajian ini dengan analisis nilai arsitektural bangunan, maka pilihan akan dipersempit hingga mendapatkan lokasi yang memenuhi kedua kriteria yang diinginkan, yaitu keterhubungan ruang dan pelestarian nilai sejarah bangunan.

\subsection{Kajian Nilai Kesejarahan dan Arsitektural Bangunan}

a. Kajian Makna dan fungsi elemen bangunan terhadap nilai sejarah arsitektur bangunan

Gedung UNPAR Jl.Merdeka No.30 Bandung adalah salah satu dari sedikit peninggalan bangunan masa periode transisi di Bandung yang tersisa. Karya arsitektur ini menjadi penting karena merupakan salah satu contoh desain bangunan yang memiliki elemen jengki dan kubisme modern didalamnya. Kombinasi kedua gaya ini yang membuat gedung ini tetap relevan hingga tanpa terasa menjadi sebuah monument yang terasing dalam lingkungan kota.

Selain itu, terdapat konsep desain pasif pada bangunan untuk mengatasi permasalahan orientasi dan penghawaan pada bangunan. hal tersebut terlihat dari elemen-elemen bangunan seperti sun shading, perltakan lubang-lubang cahaya dan angin, taman tengah serta perletakan 
dan desain jendela-jendela pada bangunan. Jika ditinjau dari masa bangunan dibangun, penerapan konsep ini merupakan hal yang cukup signifikan, bahkan untuk kondisi masa kini. Konsep desain pasif pada gedung ini dapat menjadi referensi bagi perkembangan arsitektur hijau di Indonesia

Dengan mempertimbangkan kedua hal itu, maka elemen-elemen bangunan yang merepresentasikan hal-hal tersebut pada bangunan haruslah dipertahankan dan tidak dirubah demi terjaganya nilai sejarah dan arsitektur bangunan.

\section{b. Kajian Peraturan dan ketetapan mengenai konservasi bangunan cagar budaya}

Peraturan dan ketetapan pemerintah telah menetapkan batasan-batasan yang harus ditaati untuk melakukan perubahan atau konservasi pada bangunan bersejarah. Dengan demikian mengacu pada ketetapa-ketetapan tersebut dan hasil kajian arsitektural dan sejarah bangunan maka akan didapatkan batasan-batasan tersebut.

Berdasarkan hasil kajian, terdapat bagian-bagian bangunan yang tidak dapat dirubah atau terganggu dengan penambahan fungsi baru dan ada yang dapat dirubah. Komponenkomponen bangunan yang harus dipertahankan dan dapat dirubah untuk penambahan sarana sirkulasi vertikal yang baru dan pada Gedung UNPAR Jl.Merdeka No.30 Bandung adalah sebagai berikut :

\section{1) Komponen Bangunan Yang Harus Dipertahankan}

Adalah bagian dari gedung UNPAR Jl.Merdeka No.30 Bandung yang memiliki nilai penting untuk dipertahankan karena nilai keilmuan dan sejarah yang tinggi sehingga bila dihilangkan akan mengurangi nilai penting bangunan bangunan tersebut.

Berdasarkan hasil kajian, elemen-elemen bangunan tersebut adalah :

$>$ Atap

$>$ Sun Shading

$>$ Lubang angin dan cahaya

$>$ Jendela dan pintu-pintu utama

$>$ Ornamentasi

$>$ Finishing batu alam pada bangunan utama

$>$ Komposisi bangunan

$>$ Struktur bangunan yang mempengaruhi fasad bangunan secara langsung atau ruangruang utama bangunan.

Dapat dikatakan seluruh fasad gedung UNPAR Jl.Merdeka No.30 Bandung tidak boleh berubah atau terpengaruh oleh penambahan fungsi atau sarana pada bangunan. Elemenelemen tersebut dapat dihilangkan fungsinya namun keberadaanya harus tetap dipertahankan. Salah satu contohnya adalah elemen roster, lubang angin dan cahaya dan jendela pada bangunan yang digantikan fungsinya dengan AC. Meskipun demikian, elemen-elemen bangunan tersebut harus tetap ada karena memiliki nilai sejarah dan keilmuan penting bagi bangunan.

2) Komponen Bangunan Yang Dapat dirubah atau ditambahkan Berdasarkan Kajian Nilai Sejarah dan Keilmuan Bangunan

Adalah bagian dari gedung UNPAR Jl.Merdeka No.30 Bandung yang kurang memiliki nilai yang signifikan dari segi sejarah dan keilmuan bangunan, sehingga meskipun dirubah tidak 
akan menghilangkan nilai sejarah dan keilmuan bangunan.Berdasarkan hasil kajian, elemenelemen bangunan tersebut adalah :

$>$ Pembagian ruang dengan sekat non permanen

$>$ Finishing lantai dan dinding

$>$ Utilitas bangunan

$>$ Ruang-Ruang negatif, ruang servis dan ruang yang sebelumnya telah diubah secara struktur dan fungsi sehingga tidak sama dengan desain awal.

$>$ Penambahan atau perubahan struktur pada bagian-bagian yang tidak mempengaruhi fasad atau ruang-ruang utama.

\subsection{Penempatan Sarana Sirkulasi Vertikal Berdasarkan hasil Kajian Space Syntax Dan Heritage}

Dengan memasukan analisis kajian nilai sejarah dan arsitektural, maka dari kedua lokasi yang didapatkan dari hasil Space Syntax dapat dibandingkan pengaruhnya terhadap elemen-elemen bangunan bila pada lokasi tersebut akan dimasukan sarana sirkulasi vertikal. Hasil pertimbangan tersebut adalah sebagai berikut :

Tabel 1. Pertimbangan pemasangan lift pada dua lokasi terpilih berdasarkan pertimbangan Heritage

\begin{tabular}{l|l|l} 
& Lift di Innercourt & Lift Di bekas Ruang Sekretaris \\
\hline Lokasi & $\begin{array}{l}\text { Berada di area terbuka, lokasinya } \\
\text { membuat keberadaan lift } \\
\text { membutuhkan perhatian lebih agar } \\
\text { menyesuaiakan dengan fasada } \\
\text { bangunan }\end{array}$ & $\begin{array}{l}\text { Berada di area yan tidak } \\
\text { mencolok, dan awalnya } \\
\text { merupakan bagian dari area } \\
\text { sirkulasi yang dialih fungsikan. } \\
\text { Sehingga secara konteks masih } \\
\text { sesuai sebagai penempatan } \\
\text { sirkulasi vertikal }\end{array}$ \\
\hline $\begin{array}{l}\text { Pengaruh } \\
\text { Dari Segi }\end{array}$ & $\begin{array}{l}\text { Perlu penyesuaian pada dinding } \\
\text { lantai 2 dan tiga serta akan merubah } \\
\text { Sun Shading bangunan }\end{array}$ & $\begin{array}{l}\text { Perlu penyesuaian pada lantai } 2 \\
\text { dan 3, yaitu untuk lubang lift serta } \\
\text { pit lift, namun masih sesuai } \\
\text { dengan standard yang berlaku }\end{array}$ \\
\hline $\begin{array}{l}\text { Pengaruh } \\
\text { terhadap } \\
\text { fasad }\end{array}$ & $\begin{array}{l}\text { Mempengaruhi secara langsung } \\
\text { fasad bangunan, perlu perhatian } \\
\text { tambahan agar desain lift idak }\end{array}$ & $\begin{array}{l}\text { Tidak merubah signifikan } \\
\text { tampilan bangunan karena } \\
\text { letaknya tersembunyi. Bisa } \\
\text { mengganggu identitas bangunan }\end{array}$ \\
& & $\begin{array}{l}\text { disesuaikan dengan lift kaca atau } \\
\text { dengan dinding eksisting. }\end{array}$ \\
& &
\end{tabular}

Berdasarkan tabel, disimpulkan bahwa perletakan transportasi vertikal terbaik adalah pada ruang bekas sekretaris kaprodi, pertimbangan utamanya adalah lokasi tersebut tidak mengganggu fasad sama sekali yang merupakan elemen penting pada identitas bangunan. Selain itu secara struktural, pelubangan pada lantai masih dalam koridor tata aturan yang dibolehkan selama tidak mengubah struktur utama, sedangakan penempatan pada sisi 
courtyard akan mengubah struktur dari sun shading bangunan, jendela serta dinding-dinding pada lantai 2 dan 3 dimana hal ini akan menghilangkan unsur nilai arsitektural bangunan.

\section{DISKUSI DAN PEMBAHASAN}

Penelitian menunjukan penggunaan Space Syntax dalam kajian bangunan bersejarah sangat berguna, terutama dalam analisis ruang, hal ini dikuatkan dengan penelitian-penelitian terdahulu yang menggunakan metode ini dalam penelitiannya.

Analisis Space Syntax harus diikuti oleh kajian-kajian sejarah dari objek yang terkait terutama dalam hal konservasi sehingga membuat analisis tersebut relevan. Pada studi kasus gedung UNPAR J1.Merdeka No.30 menunjukan hasil analisis Space Syntax masih bergantung pada hasil kajian nilai sejarah arsitektural bangunan. Bila lokasi-lokasi yang dihasilkan oleh analisis Space Syntax secara analisis kesejarahan tidak mendukung, maka penambahan fasilitas kecil kemungkinan untuk dilakukan. Dengan demikian penggunaan Space Syntax dalam konservasi bangunan bersejarah tetap memperhatikan kajian sejarah bangunan dan apa yang ingin dicapai dalam kajian tersebut.

Yang perlu diperhatikan adalah ketergantungan analisis Space Syntax pada Software. Dalam kajian ini keterbatasan Software membuat analisa hanya memungkinkan mengkaji dalam cakupan 2 dimensi saja. Penggunaan software Space Syntax yang dapat menganalisis secara 3 dimensi kemungkinan akan memberikan hasil yang berbeda, dengan demikian akan membuka peluang untuk penelitian lebih lanjut mengenai penggunaan Space Syntax pada kajian sejarah bangunan.

\section{KESIMPULAN}

Penelitian ini menyimpulkan bahwa :

a. Metode analisis Space Syntax memungkinkan untuk digunakan dalam kajian analisis kesejarahan bangunan, terutama kebutuhan renovasi dan konservasi bangunan bersejarah. Hasil analisa dapat digunakan untuk menentukan pola pergerakan dan area kumpul pada bangunan. data tersebut dapat dimanfaatkan untuk menentukan perletakan penambahan fasilitas seperti penempatan sirkulasi vertikal dan lain-lain.

b. Analisis Space Syntax pada bangunan bersejarah harus disertai dengan kajian tata aturan konservasi bangunan bersejarah. Kajian ini berfungsi sebagai batasan agar penambahan fasilitas dan fungsi tidak merusak nilai sejarah bangunan.

c. Kekurangan pada bagian analisa Space Syntax adalah lebih pada permasalahan software yang digunakan sehingga terdapat keterbatasan dalam proses analisa, terutama dalam hal analisa ruang dalam 3 dimensi. Di sisi lain, hal ini juga merupakan peluang untuk untuk mengembangkan metode kajian sejarah dengan Space Syntax ini lebih lanjut.

\section{DAFTAR PUSTAKA}

Adiyanto, J. (2016), Kajian Perubahan Ruang Terbuka Pada kawasan Bersejarah Dengan Metode Space Syntax (Studi Kasus : Kawasan Kampung Kapitan Palembang), Jurnal 
Perencanaan Wilayah dan Kota, Vol.27, No.2, pp.103-118, Agustus 2016, DOI : 10.5641/jrep.2016.27.2.3

Askarizad, R. (2017), Influence of Socio-Cultural Factors on The Formation of Architectural Spaces (Case Study : Historical Residential House in Iran), Creative City Design A Journal of Urban Palnning\& Design and Architecture, Vol.1, No.3

Amorim,L.,Loureiro,C.,Nascimento,C.(2007),Preserving Space: Towards a new Architectural Conservation Agenda, Proceedings, $6^{\text {th }}$ Internation Space Syntax Symposiom, Istambul.

Amorim,L.,Loureiro,C.(2007), The Space of Architecture and A New Conservation Agenda.

Griffiths, S. (2012), The Use of Space Syntax in Historical Research : Current Practice and Future Possibilities, Proceedings, $8^{\text {th }}$ Internation Space Syntax Symposiom, Santiago de Chile : PUC.

Hillier,B., Hanson.(1984),The Social Logic Of Space, Cambridge University Press, United Kingdom

Hillier, B.(1992). Natural Movement : of Configuration And Attraction in Urban Pedestrian movement London, UCl, United Kingdom

Hillier, B.(2007), Space Is The Machine, UCL, United Kingdom.

Karimi, K. (2000). Urban Conservation And Spatial transformation: Preserving the fragments Or maintaining The "Sptial Spirit". Urban Design International volume 5 pages 221-231.

Razon, AA. (2017), A Study of Space Use Pettern and Historical Residential Building Morphology of Chittagon, International Journal of Scientific \& Engineering research, Vol.8, Issue 2, Februaray 2017 ESSN-2229-5518 http://www.ijser.org/ 